\title{
A polêmica sobre a imigração no Brasil: questões de memória discursiva
}

DOl: http://dx.doi.org/10.21165/el.v48i2.2329

\author{
Patrícia Aparecida de Aquino' \\ Daiane Rodrigues de Oliveira Bitencourt ${ }^{2}$
}

\section{Resumo}

O objetivo deste artigo é analisar aspectos da polêmica sobre a imigração em diferentes momentos da história brasileira. Para tanto, o artigo fundamenta-se na perspectiva teórica da Análise do Discurso, mais especificamente, nas noções de memória discursiva (COURTINE, 1999), estereótipos (AMOSSY; PIERROT, 2001) e Semântica Global (MAINGUENEAU, 2005 [1984]). O corpus é constituído de enunciados que discutem a imigração em duas épocas diferentes: o século XIX e o século XXI. Os resultados mostram um percurso de memória em que posições são apagadas e retomadas a depender de interesses econômicos e políticos ao longo da história. Estas análises indicam que os enunciadores, ao mesmo tempo que defendem uma posição em relação a alguns grupos de imigrantes como ameaças para o Brasil, constroem uma imagem de si como cordiais, defendendo que não são preconceituosos e racistas.

Palavras-chave: estereótipo; memória; polêmica; imigração.

\footnotetext{
1 Universidade Estadual de Campinas (UNICAMP), Campinas, São Paulo, Brasil; patdeaquino@gmail.com; http://orcid.org/0000-0002-9186-8600

2 Universidade Federal do Triângulo Mineiro (UFTM), Uberaba, Minas Gerais, Brasil; daiane.unicamp@gmail.com; http://orcid.org/0000-0002-9267-1682
} 


\title{
Polemic about immigration in Brazil: discursive memory questions
}

\begin{abstract}
The purpose of this article is to analyze aspects of the controversy about immigration in different moments of Brazilian history. To do this, the paper is based on the theoretical perspective of Discourse Analysis, more specifically, in the notions of discursive memory (COURTINE, 1999), stereotypes (AMOSSY; PIERROT, 2001) and Global Semantics (MAINGUENEAU, 2005 [1984]). The corpus comprises statements that discuss immigration in two different periods: the nineteenth century and the twenty-first century. The results show a memory path in which positions are erased and retaken depending on economic and political interests throughout history. These analyses indicate that the enunciators defend a position regarding some groups of immigrants as threats to Brazil, and, at the same time, construct an image of themselves as cordial, claiming that they are not prejudiced or racist.
\end{abstract}

Keywords: stereotypes; memory; polemics; immigration.

\section{Introdução}

A América do Sul é um território de intensa imigração. Apesar disso, não há, segundo Domenech (2015), muitos estudos a respeito das políticas de controle das imigrações internacionais nessa região. Em relação ao Brasil, no final do século XIX e início do século $X X$, o país recebeu grandes contingentes, sobretudo de europeus, atraídos por uma política governamental de estímulo à imigração, que buscava substituir a mão de obra negra pelos chamados "imigrantes desejáveis", vistos como agentes de civilização e progresso, em um projeto eugenista de branqueamento físico e cultural da população. ${ }^{3}$

\footnotetext{
30 termo eugenia, proposto por Francis Galton em 1883, surge em contrapartida à noção de seleção natural de Darwin, dado que propõe uma "seleção artificial", por meio do controle de cruzamentos "indesejáveis", a fim de "melhorar" as qualidades raciais da humanidade. Com o intuito de promover esse ideal, em 1911, foi realizado em Londres o Congresso Universal das Raças. Schwarcz (2011) explica que nesse congresso foi promovida a ideia da supremacia branca em relação aos negros no que diz respeito à capacidade intelectual, embora estes fossem vistos como mais fortes fisicamente. Outro ponto defendido foi a condenação da mistura das raças, visto que o resultado desta seria uma incógnita. A pedido do então presidente do Brasil, Hermes da Fonseca, o médico João Baptista de Lacerda participou desse congresso, no qual apresentou a comunicação intitulada "Sobre os mestiços no Brasil" e defendeu que a miscigenação no Brasil seria positiva, pois produziria o mestiço que teria melhor capacidade intelectual do que o negro. Para Lacerda, com a miscigenação, em apenas três gerações, haveria um total embranquecimento da população brasileira, produzindo, segundo ele, um país civilizado e moderno. Schwarcz afırma que, nesse período, as teorias do embranquecimento da população como forma de modernização começaram a ganhar forças no Brasil. As políticas imigratórias desse período eram baseadas nessa suposta superioridade branca.
} 
Nesse contexto, explica Carneiro (2003), surgem as figuras dos "imigrantes desejáveis" e dos "imigrantes indesejáveis"; dentre estes estão diferentes raças sobre as quais incidiu e/ou incide, em determinadas épocas, a construção de uma memória discursiva depreciativa, sob diferentes rótulos: o dos doentes, o dos criminosos, o daqueles que não são aptos para o trabalho, o daqueles que podem causar encargos públicos, o dos subversivos, o dos anarquistas, o dos rebeldes.

A diferenciação entre esses dois tipos de imigrantes, pouco rememorada pelos brasileiros, foi em grande medida substituída pela noção de "Brasil Cordial", segundo Carneiro, efeito de intensas campanhas realizadas sobretudo nos anos 30 e 40 do século passado, cujo objetivo era, por meio do encobrimento de valores racistas e antissemitas das elites políticas brasileiras, promover a "construção do mito da democracia racial no Brasil", a fim de atrair os "imigrantes desejáveis", estes sim trabalhadores, que não representavam ameaça à ordem estabelecida em terras brasileiras.

Sob esse discurso ou sob essa imagem, diferentes grupos imigraram para o Brasil nos finais do século XIX e primeira metade do século XX. A presença de colônias de diferentes nacionalidades no território brasileiro somada à miscigenação entre alguns estrangeiros com os nativos contribuiu para reforçar o chamado, por alguns, de "mito de país cordial".

No início do século XXI, passa a haver grandes fluxos migratórios e o Brasil volta a receber um grande contingente de pessoas em busca de trabalho, vindas, principalmente, de outros países da América Latina, muitos na condição de "refugiados", o que, por um lado, reaviva o discurso polêmico a respeito da entrada de imigrantes no país e, por outro, atualiza a noção de "imigrantes indesejáveis", a qual, segundo Domenech (2015), passa a ser enunciada sob a forma de "novas ameaças": o narcotráfico, o terrorismo, o tráfico de pessoas e a migração não documentada.

Tendo isso em vista, o objetivo deste artigo é, a partir de um conjunto de enunciados sobre imigrações, analisar aspectos da polêmica em torno dos diferentes movimentos imigratórios, em diferentes momentos históricos. Para tanto, reflete sobre a construção de diferentes memórias discursivas a respeito da representação dos imigrantes e das posições dos brasileiros em relação a esses grupos. Em outras palavras, este artigo busca, com base na comparação entre enunciados de duas épocas (séculos XIX e XXI), analisar a construção de memória(s) discursiva(s) a respeito da polêmica que envolve imigrantes "desejáveis" e "indesejáveis" no Brasil.

Nas análises, partimos do pressuposto de que os posicionamentos em confronto em um discurso polêmico são regidos por uma semântica global (MAINGUENEAU, 2005 [1984]) no interior da qual a tentativa de tradução do discurso do outro conduz, obrigatoriamente, à formulação de simulacros. Mobilizamos também a discussão de Amossy e Pierrot (2001) acerca dos estereótipos na perspectiva da Análise do Discurso e as postulações de 
Courtine (1999) a respeito do funcionamento da memória discursiva. O artigo estruturase do seguinte modo: primeiramente, resumimos o referencial teórico e descrevemos a metodologia adotada. A seguir, analisamos enunciados sobre os imigrantes no século XIX e depois no século XXI. Por fim, apresentamos as conclusões da pesquisa.

\title{
Memória discursiva e estereótipos
}

Amossy e Pierrot (2001) explicam que o estereótipo funciona como uma representação indispensável para mediar a relação com o real, como forma de filtrar a realidade, expressando o imaginário social. Para as autoras, a noção pode ser produtiva nos estudos da Análise do Discurso $(A D)^{4}$ na medida em que permite analisar a articulação entre 0 linguístico e o social. Por relacionar-se às noções de pré-construído e interdiscurso, a noção de estereótipos permite analisar como imagens discursivas cristalizadas funcionam (são retomadas e deslocadas) no espaço da memória. Nesse espaço, os estereótipos retomam e reforçam imagens cristalizadas de grupos e lugares, permitindo a circulação de categorizações como "um chinês", "um latino", "um brasileiro", que produzem, retomam e põem em circulação determinados discursos sobre a identidade desses povos.

Assim como aquilo que se enuncia é responsável pela construção de uma memória, aquilo que é esquecido ou silenciado também tem um papel muito importante para tal construção. Lidamos com a noção de esquecimento (COURTINE, 1999), de extrema relevância para a compreensão dos dados aqui analisados. Para explicá-la, resumimos a história narrada por Kundera e recontada por Courtine no texto "O chapéu de Clémentis":5 o dirigente comunista Klement Gottwald discursava da sacada de um palácio em Praga em um fevereiro de 1948, com muito frio e sob neve. Ao seu lado, estava o também comunista Clémentis, o qual, muito solícito, tirou seu gorro de pele e o colocou na cabeça de Gottwald. Centenas de milhares de exemplares da fotografia de Gottwald, com o gorro de pele e ao lado de seus camaradas, dentre os quais Clémentis, foram reproduzidas pelo departamento de propaganda. Quatro anos mais tarde, porém, Clémentis foi enforcado, depois de ter sido acusado de traição. Nas palavras de Kundera,

\begin{abstract}
4 Amossy e Pierrot (2001) explicam que a noção de estereótipo foi proposta por Lippmann no início do século XX. Essa noção foi lida por alguns psicólogos sociais como associada a uma representação pejorativa, redutora e nociva, pois simplificaria o real. Entretanto, as autoras defendem que a esquematização e a categorização, mesmo quando simplificam excessivamente, são procedimentos indispensáveis para a relação com o outro. Além disso, destacam que, mesmo que em seu início os estudos da AD tenham tido pouco interesse pelos estereótipos, seus pressupostos teóricos, como os de que o sujeito não é a fonte do sentido e de que os sujeitos estão inscritos em contextos determinados, permitem estabelecer tal relação.
\end{abstract}

5 No texto "O chapéu de Clémentis", Courtine (1999) apresenta a abertura da primeira parte de "O livro do riso e do esquecimento", em que Milan Kundera (1987 [1978], p. 9) narra "um momento fatídico que ocorre uma ou duas vezes por milênio", quando o líder comunista Klement Gottwald faz seus discursos. 
[...] o departamento de propaganda imediatamente fez com que ele desaparecesse da História e, claro, de todas as fotografias. Desde então, Gottwald está sozinho na sacada. No lugar em que estava Clémentis não há mais nada a não ser a parede vazia do palácio. De Clémentis, só restou o gorro de pele na cabeça de Gottwald. (KUNDERA, 1987 [1978], p. 9).

Segundo Courtine (1999, p. 15), pode-se observar nessa narrativa e nesses registros fotográficos o "apagamento da memória histórica que deixa, como uma estreita lacuna, a marca de seu desaparecimento". Essa "estreita lacuna" não foi fruto de um acaso, ao contrário, foi produzida no exato instante da sua tentativa de apagamento.

Diferentemente do caso do chapéu (ou gorro de pele) de Clémentis, não dispomos de fotografias das tentativas de apagamento com as quais lidaremos neste texto, mas encontramos registros de outra natureza: a impressão de determinados textos de História da Imigração no Brasil. Analisamos a contribuição dessa tentativa de apagamento para a construção de estereótipos; em outras palavras, veremos como, a fim de construir o mito de que o Brasil é um país cordial, alguns enunciados tiveram destino semelhante ao de Clémentis nas fotografias que registraram o discurso proferido por Gottwald.

\section{Metodologia}

Maingueneau (2006, p. 16) defende que um corpus de pesquisa pode ser agrupado em unidades tópicas, que correspondem a espaços institucionais já pré-definidos, ou em unidades não-tópicas, isto é, "unidades construídas pelos pesquisadores independentemente de fronteiras preestabelecidas", mas profundamente inscritas na história. O corpus desta pesquisa corresponde a esse segundo grupo. Foram selecionados dois conjuntos de enunciados que tratam da imigração no Brasil, divididos em dois períodos: um do final do século XIX e início do século XX e outro do início do século XXI. Esses enunciados foram produzidos por diferentes enunciadores e em diferentes gêneros discursivos, a saber, trechos de livros de história, declarações de políticos, panfleto, selo e comentário da internet, formando, assim, uma unidade não-tópica, que não corresponde a espaços pré-definidos, nem a uma instituição específıca, mas abriga um conjunto variado de gêneros de discursos, porta-vozes e campos sobre a imigração no Brasil.

Esses dois conjuntos foram descritos e analisados a partir da noção de estereótipo, a fim de identificar a imagem discursiva de imigrantes desejáveis e indesejáveis em circulação nos diferentes períodos estabelecidos como recorte para o corpus. Essa identificação permitiu comparar e contrapor esses dois conjuntos, possibilitando delinear aspectos da configuração da memória discursiva sobre a imigração no Brasil. 


\section{Brasil cordial}

Alguns autores (por exemplo, Holanda (2010 [1959]) e, mais recentemente, VilelaArdenghi e Motta (2103)) já se detiveram sobre o mito de que o brasileiro seria um povo cordial e sobre as motivações que teriam levado à construção desse estereótipo. Não aprofundaremos a análise dessa construção como um todo, apenas no que se refere a um de seus aspectos: o do esquecimento (ou apagamento) necessário para que sua circulação fosse promovida. Vejamos, por exemplo, marcas desse discurso em funcionamento no século XIX:

(1). No espírito brasileiro, felizmente, não criou nunca raízes o preconceito de raça. É um dos traços nacionais de que podemos nos orgulhar. Judeus, cristãos-novos, ciganos, todos os antigos "infames", fundiram-se na população, absorvidos e diluídos. ... Só recentemente, por estupidez e espírito de imitação simiesca, tem-se procurado injetar preconceitos racistas de origem alienígena. É muito engraçado êste racismo numa população mestiça resultante de franca miscigenação humana. (COARACY, 1955, p. 99-100).

Em (1), o enunciador assume, em tom orgulhoso (felizmente), a característica atribuída ao brasileiro: a de um povo não preconceituoso, que aceitaria diferentes crenças e culturas: judeus, cristãos-novos, ciganos e os chamados "infames". ${ }^{6}$ Desse modo, se há algum traço de racismo no brasileiro, este teria sido "importado", trazido de outros povos, devido à estupidez ou a "um espírito de imitação simiesca". Esses enunciados merecem duas observações: a primeira delas é a de que sua existência indica a necessidade de uma resposta a um outro discurso, segundo o qual haveria, sim, preconceito(s) por parte do brasileiro. A segunda refere-se ao fato de que eles estão na página 99 do livro, porém, o próprio autor, sem que se dê conta disso, já havia apresentado (na página 90) um dado que denuncia o racismo contra os negros e os mulatos (excerto 2), um preconceito do qual o autor do relato se distancia, pois seriam manifestações pouco cristãs:

(2). Foi por esse tempo que uns pretos que haviam formado a Irmandade de São Domingos desavieram com os cônegos da Sé (a igreja de São Sebastião, no morro do Castelo)... Parece que os do Cabido, manifestando preconceitos de côr muito pouco cristãos, menoscabavam os crioulos e dificultavam-lhes a prática de suas devoções (COARACY, 1955, p. 90).

6 Segundo o autor, "os 'infames', na expressão da legislação da época, eram o que poderíamos chamar de cidadãos de terceira classe, casta ínfıma, tolerados mas não incluídos na comunidade, com direitos castrados, proibidos de exercer cargos públicos e que só podiam residir em bairros determinados, em isolamento, como lázaros". (COARACY, 1955, p. 98-99). 
Da perspectiva de Coaracy (1955), portanto, seríamos um país cordial e cristão, ainda que com manifestações pontuais (cuja procedência seria alienígena) de preconceito. Havia, porém, a circulação de enunciados que questionavam explicitamente a noção de cordialidade nacional, como exemplificado pelo excerto 3 , do qual se infere que o enunciado presente no excerto 1, sobre a "origem alienígena" do preconceito no Brasil, não era um enunciado isolado, mas circulava no interior de uma polêmica, em uma constante resposta ao seu outro.

(3). A meu ver, quem faz esse preconceito são as famílias tradicionais brasileiras, e não o estrangeiro. 0 estrangeiro que pratica 0 preconceito contra o negro aprende com os brasileiros. Haja visto que os filhos de estrangeiros não ouviram de seus avós ou de seus pais o modo com que tratavam os negros na escravidão. Ao passo que aquelas famílias tradicionais de Campinas, mesmo já pela sua tradição, pela sua influência nos filhos já contaram o modo por que tratavam os negros desta maneira; eles trazem na sua mentalidade, os netos dos escravocratas, o mesmo conceito que aprenderam de seus avós. ${ }^{7}$

Em meio a essa polêmica que, como evidenciado pelos exemplos, envolve sobretudo o imigrante negro, há um grande incentivo para a vinda de estrangeiros (europeus e brancos), a fim de que assumam o trabalho nas lavouras brasileiras. Para tanto, o governo realiza uma grande campanha de promoção dessa imigração específica, como exemplificado pelo panfleto distribuído na Itália, que convidava o imigrante a vir construir seus sonhos com a família no Brasil.

7 Dr. Francisco Lucrécio (médico em pronunciamento público), in Fernandes (2008 [1964], p. 673). 


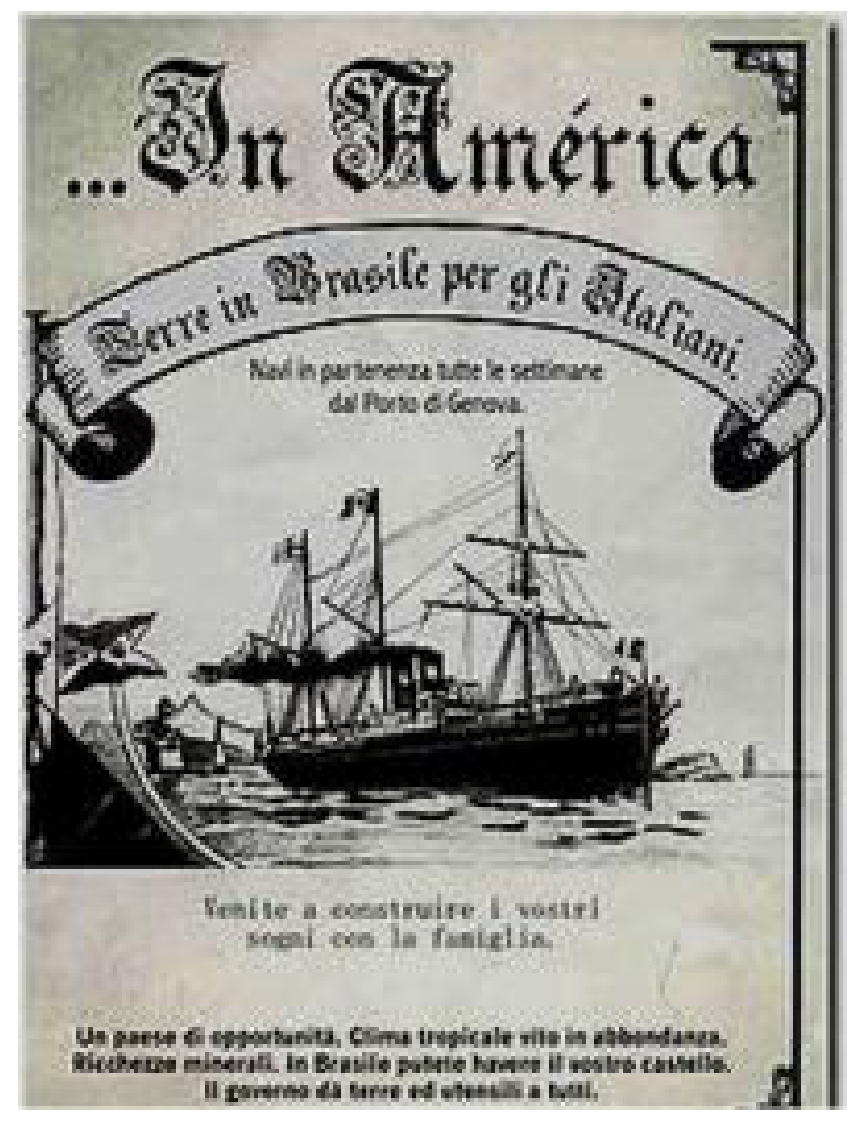

Figura 1. Panfleto de estímulo à imigração para o Brasil

Fonte: https://imigracaohistorica.com/imagens-imigracao/. Acesso em: 29 mai. 2019.

Essa promoção faz parte de um discurso sobre o branqueamento e a civilização do Brasil, em uma posição que associa o fato de ser europeu (desde que branco) ao fato de ser civilizado, e essa associação leva ao desenvolvimento das já mencionadas políticas eugenistas e higienistas. ${ }^{8}$

Noções de "cordialidade", "acolhimento" e respeito ao outro eram não só polêmicas, mas, de acordo com Carneiro (2003), faziam parte de uma estratégia de consolidação da imagem do Brasil como uma nação harmônica e em progresso, imagem necessária para atrair contingentes de "imigrantes desejáveis" de forma a suprir a mão de obra necessária para

8 Ao analisar as relações entre saúde e imigração no Brasil de uma perspectiva histórica, Granada et al. (2017) mostram, por exemplo, que, em meados do século XIX, por conta do projeto de branqueamento da população, o governo brasileiro desenvolveu uma política mais ofensiva para combater a febre amarela, que era mais letal para imigrantes vindos da Europa, do que a política para combater a tuberculose e a varíola que assolavam mais fortemente a população negra. Desse modo, havia uma maior preocupação com a saúde dos imigrantes desejáveis, marcada por uma ideologia eugenista e higienista. 
os trabalhos anteriormente realizados pelos escravos, em outras palavras, para atender aos interesses das elites, tanto a agrária quanto a industrial. Para alguns proprietários, não importava a procedência dos imigrantes, como exemplificado em 4, mas mesmo o discurso desses "não preconceituosos" fazia circular uma imagem negativa dos negros e mulatos brasileiros, como a declaração de Olintho José Meira, um agricultor do Rio Grande do Sul, discutida por Teixeira (2016, p. 5-6):

(4). Em sua opinião, não se deveria esperar que os filhos de escravos fossem eficazes no trabalho da grande propriedade, porque se tornariam livres e iriam à procura de outras experiências. Dos retirantes das secas também não tinham muito o que esperar, pois a maioria não era elemento digno de nota e a lavoura não os conservaria, talvez aqueles impossibilitados de regressar às províncias mais longínquas; estes poderiam conservar-se nas novas posições. Meira defendia que, para suprir a falta, o Brasil deveria buscar braços em outros países. Para ele, não importava a procedência, o que interessava é que os imigrantes fossem vigorosos e afeitos ao trabalho.

A mão de obra negra e mulata é descrita como sem valor, assim como a mão de obra do retirante que não seria boa para o trabalho nas lavouras. Esse excerto comprova o que Carneiro (2003, p. 3) denuncia a respeito do discurso preconceituoso em relação aos negros e permite que reconheçamos que tal discurso se estende aos retirantes nordestinos:

Preocupadas em trazer para o Brasil o melhor dos imigrantes, as elites republicanas não previram a incorporação do negro no mundo do trabalho livre e, com isso, ele foi sendo proletarizado e abandonado sem condições de superar o problema racial, ato fundamental para o seu processo e mudança social. O negro deixou sua condição de escravo para se tornar proletário, e, até mesmo, mendigo, louco ou desclassificado.

Sem que isso seja explicitado, enunciados como o do excerto 4 fazem parte da delimitação do discurso que justificaria a segregação, ao mesmo tempo em que contribuem para delimitá-lo, para reforçá-lo, por meio da rememoração. É essa memória, por sinal, que se tem visto atualizada a respeito dos negros no Brasil, em uma aparentemente eterna polêmica que hoje é reavivada quando se questiona, por exemplo, a meritocracia ou se propõem políticas de cotas no Brasil.

Um caso peculiar, por se diferenciar significativamente do dos negros, é o dos chineses, que passamos a abordar a seguir. 


\section{A imigração dos chineses: deslocamentos e apagamentos}

Também no final do século XIX houve uma política de incentivo à vinda de chineses para o Brasil. Carneiro (2003, p. 2) relata que um Congresso Agrícola sobre a imigração, realizado em 1878, fez circular "uma série de impressos que cuidaram de documentar os diferentes apartes pró e contra os chineses e favoráveis à adoção de uma política imigratória seletiva". Fundamentados em um ideal de nação brasileira branca e civilizada, a polêmica sobre os chineses ficou conhecida como "a questão chinesa", em que o chinês foi descrito pelos abolicionistas como "pior que o negro: avaro, viciado em jogo e ópio, infanticida por convicção e ladrão por instinto" (Ibid., p. 2). Ainda de acordo com Carneiro, para Souza Mello (apud CARNEIRO, 2003, p. 2), Diretor da Repartição Geral das Terras Públicas, os brasileiros deveriam ficar felizes por se livrarem "dessa importação de semelhante gente que de certo ninguém receberá".

Azevedo (2008, p. 73) também analisou o mesmo período histórico e se deparou, em uma tese aprovada com distinção pela Academia de Medicina do Rio de Janeiro, com a afırmação de que o Brasil só encontraria o progresso material, moral e intelectual se examinasse melhor o povo que lhe convém que "certamente não seriam os africanos e muito menos os chineses".

Essa imagem a respeito dos chineses pode provocar estranhamento, pois tal memória negativa sobre os chineses no Brasil foi em grande medida apagada. Atualmente, tem havido comemorações da presença chinesa no Brasil, nas quais o discurso retomado é aquele que recupera não o momento da discriminação e do preconceito, o qual, como o chapéu de Clémentis, tem sido apagado, mas um momento histórico anterior ao dos enunciados preconceituosos aqui mencionados: retoma-se o período do reinado de $\mathrm{D}$. João, quando teriam sido trazidas, entre 1810 e 1812, seis famílias para o cultivo do chá no Jardim Botânico. A memória evocada, portanto, é a de um convite especial que demandava não uma mão de obra braçal que substituiria a escrava, mas uma mão de obra especializada para a produção de uma bebida apreciada pelos nobres.

Em comemoração ao bicentenário da imigração chinesa, foi emitido um selo bilíngue. Neste, aparecem as cores das bandeiras dos dois países e elementos das duas culturas perfeitamente integrados: como representante da cultura chinesa, um dragão que contorna o morro do Pão de Açúcar e personagens de crianças sorridentes com traços e roupas orientais, uma delas levantando uma grande bola de futebol verde e amarela na terra firme da baía da Guanabara, contornada por um braço de mar pelo qual se aproxima uma embarcação branca, à semelhança das embarcações chinesas. 


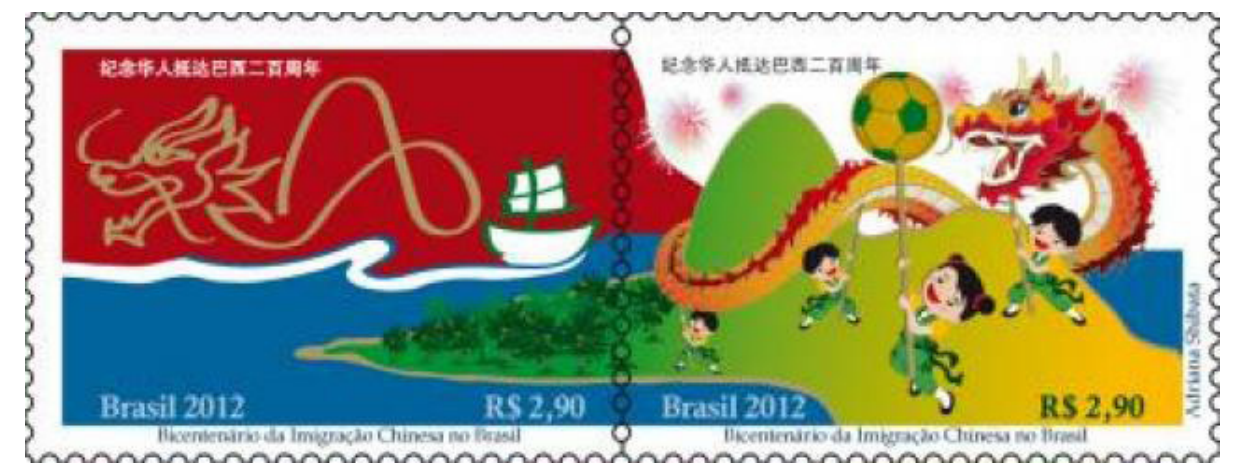

Figura 2. Selo comemorativo do bicentenário da imigração chinesa no Brasil

Fonte: http://www.selosefilatelia.com.br/PastaLancamentos2012/020.html. Acesso em: 29 mai. 2019

Não é apenas o selo comemorativo que recupera uma imagem positiva e feliz da imigração chinesa. No dia 05 de maio de 2018 foi proposta, pelo vereador Marcos Bernadelli, a criação do dia do imigrante chinês em Campinas. Não houve polêmica em relação à proposta, e a argumentação versava em torno de enunciados que destacavam a experiência dos chineses, como exemplificado nos excertos a seguir:

(5). "[...] tiveram um papel bastante importante. Eles tinham bastante experiência com essa área. - foi fundada uma companhia de comércio chinês para dar suporte para a vinda desses chineses que se estabelecerem lá (no jardim botânico, para o cultivo de chá)". ${ }^{9}$ (Destaques nossos).

Em 06 de junho de 2018, a proposta foi aprovada e um dos discursos oficiais sobre a aprovação, que novamente retoma a "experiência", com a qual nós teríamos a aprender, é o seguinte:

(6). "A China é hoje indiscutivelmente um dos maiores parceiros comerciais do Brasil e lá poderemos aprender muito sobre a cultura, a economia e até a língua chinesa. Espero poder representar a Câmara com muita honradez e orgulho nas atividades, e trazer de lá experiências que possam ser aplicadas em nossa cidade". ${ }^{10}$ (Destaques nossos).

9 Alexandra Caprioli (Diretora do Departamento de Turismo de Campinas em Audiência Pública (Consulta Pública): Dia do Imigrante Chinês 11/05/2018).

10 Pedro Tourinho (vereador de Campinas, Câmara aprova Dia do Imigrante Chinês, primeira data comemorativa que passou por audiência pública, e vereador Tourinho irá representar o Legislativo em Seminário na China, 06 de junho de 2018). 
A figura dos imigrantes chineses passou, portanto, de indesejável a desejável e, para a construção desse novo estereótipo - agora o de povo experiente -, foi necessário apagar outros discursos dos quais restaram apenas alguns vestígios, como o do chapéu de Clémentis, que não foi possível apagar das fotografias do discurso de Gottwald. Diferentemente do caso narrado por Kundera, os enunciados proferidos contra os chineses não tiveram grande divulgação e ficaram restritos aos textos acadêmicos de história, o que contribuiu ainda mais para a facilidade de sua substituição pelo discurso que tenta construir a imagem do "gigante asiático", uma substituição que coincide com novos interesses econômicos das elites brasileiras (agrárias, industriais e políticas) atuais, em um momento em que a "parceria" com a China pode ser traduzida pelo investimento chinês em diversas grandes empresas no Brasil.

Quando não há interesses dessa natureza em jogo, os discursos - dentre os quais os oficiais - sobre grupos de imigrantes podem ser radicalmente distintos, como veremos a seguir.

\section{Alguns imigrantes da América do Sul}

Dada a proximidade geográfica e as oscilações das políticas econômicas na América Latina, tem havido, nas primeiras décadas do século XXI, grandes fluxos migratórios nessa região. Tanto de estrangeiros para o Brasil, como de brasileiros para o exterior. ${ }^{11}$ No caso da migração recente para o nosso país, temos nos deparado com diferentes "rememorações" do que acontecia no séc. XIX: por um lado, veio à tona a polêmica em relação à entrada (agora muito enunciada como "acolhimento"), dos estrangeiros, e no interior dessa polêmica há a rememoração e/ou a atualização de alguns daqueles enunciados proferidos no passado, com manifestações, por vezes explícitas, de preconceito.

Por outro lado, deflagram-se casos de escravidão - a chamada "escravidão contemporânea". Contra esse crime, destaca-se a ação do programa "Escravo, nem pensar", ${ }_{12}$ que não apenas o denuncia, mas promove ações em parceria com outras instituições, dentre elas, a realizada com uma escola pública da capital paulista, que realizou um projeto interdisciplinar sobre o tema imigração, a fim de desconstruir

11 A título de exemplificação, houve, de acordo com o Relatório de dezembro de 2017 da Organização das Nações Unidas (ONU), 6.119 brasileiros que migraram para a Venezuela, enquanto 3.515 venezuelanos haviam migrado para o Brasil na primeira metade de 2017.

12 O Escravo, nem pensar! (ENP!), um programa da ONG Repórter Brasil, é o primeiro programa educacional de prevenção ao trabalho escravo a atuar em âmbito nacional. Disponível em: http://reporterbrasil.org.br/quem-somos/. Acesso em: 22 set. 2018. 
estereótipos em relação a determinados povos, por exemplo, a associação - naturalizada, segundo uma das professoras participantes do projeto - que se passava a estabelecer entre os bolivianos e o trabalho escravo. ${ }^{13}$

Passaremos a analisar alguns enunciados contrários à entrada ou permanência de latinoamericanos no Brasil. O primeiro excerto selecionado corresponde a um comentário de um leitor a um texto de Sakamoto, no qual o jornalista, presidente da ONG Repórter Brasil, que posteriormente (em 2017) veio a ser premiado pela sua atuação contra o trabalho escravo, havia reivindicado mudanças no antigo Estatuto do Estrangeiro, a fim de que o trabalho dessas pessoas no Brasil fosse regularizado, o que eliminaria os instrumentos coercitivos comumente utilizados por donos das oficinas de costura que há mais de uma década "contratam" não só brasileiros, mas estrangeiros, principalmente bolivianos. Segundo um leitor, o Sakamoto errava ao reivindicar a regularização do trabalho dos bolivianos:

(7). Esse reporter com certeza nunca viveu na Bolivia, porque os brasileiros que la vivem sao descriminados pelos bolivianos e mal tratados, portando estes bolivianos sem qualquer qualificacao profissional devem retornar a seu pais de origem e nao perderem seu tempo reclamando do emprego aqui no Brasil. ${ }^{14}$

O argumento do internauta é o de que os bolivianos não teriam "qualquer qualificação profissional" e isso, somado ao fato de que os brasileiros também seriam discriminados na Bolívia, justificaria a saída desses estrangeiros do Brasil. O comentarista não afırma que eles devem ser expulsos ou que deveria haver uma ação governamental para a retirada desses imigrantes: "eles devem retornar a seu país de origem", o que poderia ser interpretado como uma frase isenta de qualquer discriminação se for considerado que eles perderiam "seu tempo reclamando no emprego aqui no Brasil...", ou seja, eles sequer estariam satisfeitos. O que é denunciado por Sakamoto como "escravidão" é retomado pelo comentarista como "emprego", o que sugere que os estrangeiros estariam ameaçando um direito dos brasileiros - que, por dedução, talvez se satisfizessem com as condições oferecidas. Desse modo, constrói, em oposição à imagem do nativo, uma imagem do imigrante como insatisfeito, inconformado e ingrato. Há, por parte do enunciador, uma tentativa de preservar a própria imagem: ele não está sendo injusto nem tomando uma iniciativa discriminatória, ao contrário, ele se identifica com os brasileiros

13 Detalhes sobre esse projeto podem ser vistos no vídeo "Migração como direito humano: Rompendo o vínculo com o trabalho escravo.". Disponível em: http://bit.ly/2Xt/56y. Acesso em: 22 set. 2018.

14 Comentário de leitor "abm" (postado em 17/12/2007) ao final do texto "Quando o país vai tratar com dignidade os 'seus' bolivianos?", Sakamoto. Disponível em: http://bit.ly/2S187NA. Acesso em: 12 abr. 2018. (mantivemos a escrita original). 
que também seriam alvo de discriminação, sugere inclusive que experienciou ser vítima de preconceito - afinal, o Sakamoto, ao contrário dele, estaria tratando de um tema sem o devido conhecimento - e, com base em dados concretos, "apenas" se manifesta a favor de que esses estrangeiros voltem (voluntariamente, podemos presumir) para a sua terra natal.

Mais recentemente, em 2018 - exatamente no mesmo ano em que houve a aprovação do dia do imigrante chinês em uma grande cidade brasileira -, podemos nos deparar, em diversos meios de comunicação, com a polêmica em torno da imigração de venezuelanos. A porta de entrada para estes é o estado brasileiro de Roraima, que, como amplamente difundido nos noticiários nacionais, está recebendo um contingente exorbitante de venezuelanos. A respeito dessa entrada, a governadora do estado de Roraima, Maria Suely Silva Campos, defende um forte controle da fronteira. Selecionamos para análise o seguinte excerto:

(8). "O Estado está já impactado, ele está sobrecarregado. Como é que o menor Estado da Federação, nós temos 520 mil habitantes, de repente nós temos um acréscimo de 10 por cento da nossa população", disse, em entrevista coletiva em Brasília. Para a governadora, falta na fronteira um controle maior sobre quem entra no país por parte do governo federal. "Exigir o cartão de vacinação, exigir antecedentes criminais, documentação, inspeção de veículos, de pessoas, temos que ter uma medida de conter esse fluxo". ${ }^{15}$

Primeiramente, a governadora, em tom alarmista, recorre a números para justificar seu pedido de maior controle na fronteira, a fim de evitar maior "impacto" ao "menor Estado da Federação", já populacionalmente "sobrecarregado". A seguir, sugere medidas para "conter esse fluxo" e essas medidas rememoram, ainda que possa não haver consciência sobre esse fato, os estereótipos construídos em relação aos "imigrantes indesejáveis", pois a documentação exigida pode ser traduzida ou parafraseada da seguinte maneira: a carteira de vacinação evidenciaria que alguns imigrantes são vacinados, mas outros não seriam, ou seja, apresentam risco de transmissão de doenças, em outras palavras, poderiam ser considerados doentes em potencial. Os "antecedentes criminais", por sua vez, pressupõem que há a possibilidade de que o imigrante seja criminoso.

15 Paraguassu, L. "'Tenha santa paciência", diz ministro sobre ação de RR contra venezuelanos" Terra. Disponível em: http://bit.ly/2RXh5LN. Acesso em: 13 abr. 2018. 
Cabe observar que a governadora não explicita preconceitos ou discriminação em relação aos venezuelanos propriamente ditos; ela estaria preocupada não com a entrada específica de nativos da Venezuela, ela sequer recorre aos termos "imigrantes" ou ao gentílico "venezuelano", em vez disso, recorre aos termos "população", "pessoas" e "fluxo". A preocupação da governadora se dirige à entrada daqueles que - com base em inspeções presumivelmente compatíveis e adequadas - pudessem pôr em risco a saúde e a segurança dos brasileiros ou, em outras palavras, com a entrada daqueles que não viessem a ser classificados como prováveis "cidadãos de bem" em terras brasileiras. Isso é coerente com a observação de Domenech (2015), de acordo com a qual, dentre os critérios para a seleção dos imigrantes desejáveis, as condições de saúde têm sido uma preocupação para as políticas de imigração.

Sendo assim, a posição da governadora, à semelhança dos enunciados do século XIX que analisamos anteriormente, ainda que de forma não explícita, acaba por rememorar um estereótipo negativo do imigrante como perigoso, doente, possível criminoso, enfim, uma ameaça para a segurança do país. Por meio do mesmo recurso utilizado no século XIX, questões de natureza diversa são tomadas como argumentos para tentar evitar a entrada de determinados grupos específicos. Segundo Domenech (2013), é comum que as políticas de imigração utilizem o argumento de defesa dos direitos humanos como pretexto para um melhor controle e administração dos fluxos migratórios.

Desta vez, não se pretende controlar a entrada por uma questão racial, mas econômica: os nossos vizinhos não vêm oferecer suas experiências ou investir nas empresas aqui estabelecidas, mas estão em busca de trabalho e, com isso, são vistos por parte dos brasileiros como uma ameaça. Bracante e Reis (2009, p. 77) discutem o processo de securitização, isto é, "o processo político intelectual de identificação de um objeto como ameaça, concluindo, assim, que o assunto deve passar a constar no domínio (e na agenda) da segurança". Desse modo, como explicam os autores, a segurança é um ato de discurso, no sentido de que as ameaças não são "reais", mas "percebidas" por um agente securizante, que define os critérios de ameaças, fazendo com que tal declaração já seja suficiente para que o Estado possa ter o direito de utilizar meios extraordinários para lidar com os imigrantes, como a inspeção, a separação de pais e filhos e a deportação. Assim, os critérios de securitização, embora produzam o efeito de sentido de neutralidade, podem ser compreendidos ou enunciados como frutos de escolhas políticas.

\section{Conclusão}

A análise permitiu traçar um percurso de memória em que enunciados são apagados e retomados, relacionados à questão de raça e da procedência, a depender dos interesses econômicos em jogo. 
Diferentemente dos enunciados explicitamente preconceituosos, como os proferidos por personalidades públicas do séc. XIX, atualmente, os enunciados, aparentemente neutros (por serem institucionalizados), cumprem o papel de dificultar - por vias burocráticas ou selecionar a entrada de imigrantes. A análise dos excertos contemporâneos indica também que seus enunciadores levam em conta que enunciam no interior de uma polêmica, fundamentada em uma retórica multiculturalista, na qual afirmar que um determinado grupo não deve ter acesso livre ao Brasil costuma ser interpretado como aquilo que, da perspectiva de um dos posicionamentos em confronto, corresponde a um simulacro: a manifestação de preconceito e/ou discriminação. Buscando evitar essa interpretação e afastar-se de uma imagem negativa, os enunciadores lançam mão daquilo que, de seu ponto de vista, são argumentos suficientes para esclarecer que não se trata nem de preconceito nem de discriminação, mas de uma preocupação com a situação do Brasil ou dos brasileiros. Desse modo, tentam sustentar a imagem do brasileiro receptivo e acolhedor que, se profere enunciados não condizentes com essa imagem, o faz em determinadas circunstâncias específicas, talvez em caráter de exceção. Por outro lado, continua havendo a construção de duas imagens de imigrantes, de um lado, os desejáveis, por questões políticas e/ou econômicas, que são vistos em plena harmonia com os ideais brasileiros, e, de outro, os indesejáveis, caracterizados, ainda que na maioria das vezes de forma indireta, como insatisfeitos, ingratos, doentes e perigosos.

De acordo com nossas análises, há pouco de intrínseco aos grupos raciais que os levem a assumir a posição de imigrantes desejáveis ou indesejáveis. São interesses econômicos (portanto, variáveis) os que movem a construção ou, como vimos no caso da imigração chinesa, o apagamento de determinadas memórias a respeito de diferentes grupos de imigrantes.

\section{REFERÊNCIAS}

AMOSSY, R.; PIERROT. A. H. Estereotipos y clichés. Buenos Aires: Eudeba, 2001.

AZEVEDO, C. M. M. Onda negra, medo branco: o negro no imaginário das elites, século XIX. São Paulo: Annablume, 2008.

BRACANTE, P. H.; REIS, R. R. A "securitização da imigração": mapa do debate. Lua Nova, São Paulo, n. 77, p. 73-104, 2009.

CARNEIRO, M. L. T. A imagem do imigrante indesejável. In: SEMINÁRIOS - IMIGRAÇÃO, REPRESSÃO E SEGURANÇA NACIONAL, São Paulo: Arquivo do Estado/Imprensa Oficial do Estado de São Paulo, n. 3, p. 23-44, out. 2003.

COARACY, V. Memórias da Cidade do Rio de Janeiro. Rio de Janeiro: Editora José Olympio, 1955. 
COURTINE, J. J. O Chapéu de Clémentis. Observações sobre a memória e o esquecimento na enunciação do discurso político. In: INDURSKY, F. (org.). Os múltiplos territórios da análise do discurso. Porto Alegre: Editora Sagra Luzzato, 1999.

DOMENECH, E. Las migraciones son como el água: hacia la instauracion de políticas de control com rostro humano. Polis, n. 35, p. 1-20, 2013.

DOMENECH, E. O controle da imigração "indesejável": expulsão e expulsabilidade na América do Sul. Ciênc. Cult., São Paulo, v. 76, n. 2, p. 25-29, abr./jun. 2015.

FERNANDES, F. A integração do negro na sociedade de classes: no limiar de uma nova era. v. II. São Paulo: Globo, 2008 [1964].

GERALDO, E. A "lei de cotas" de 1934: controle de estrangeiros no Brasil, Cad. AEL, v. 15, n. 27, p. 173-209, 2009.

GRANADA, D. et al. Discutir saúde e imigração no contexto atual de intensa mobilidade humana. Interface, v. 21, n. 61, p. 285-296, abr./jun. 2017.

HOLANDA, S. B. Visão do paraíso: os motivos edênicos no descobrimento e colonização do Brasil. São Paulo: Companhia das Letras, 2010 [1959].

KUNDERA, M. O Livro do Riso e do Esquecimento. Rio de Janeiro: Editora Nova Fronteira, 1987 [1978].

MAINGUENEAU, D. Cenas da enunciação. Curitiba: Criar Edições, 2006.

MAINGUENEAU, D. Gênese dos discursos. Curitiba: Criar Edições, 2005 [1984].

SCHWARCZ, L. M. Previsões são sempre traiçoeiras: João Baptista de Lacerda e seu Brasil branco. Hist. Cienc. Saúde-Manguinhos, Rio de Janeiro, v. 18, n. 1, p. 225-242, mar. 2011.

TEIXEIRA, R. S. Imigração de trabalhadores estrangeiros no Nordeste, final do século XIX e início do século XX. Anais do XXIII Encontro Regional da Anpuh/SP: História: por quê e para quem? São Paulo, v. 1, p. 1-18, 2016.

VILELA-ARDENGHIE, A. C.; MOTTA, A. R. Brasil-paraíso: estereótipo e circulação. D.E.L.T.A., São Paulo, v. 29, n. 3, p. 381-404, 2013. 